\title{
Characteristics of Impaired Chemotactic Function in Cord Blood Leukocytes
}

\author{
TATSUHITO TONO-OKA, ${ }^{(15)}$ MASAYUKI NAKAYAMA, HIDEKI UEHARA, AND SHUZO \\ MATSUMOTO \\ Department of Pediatrics, Hokkaido University School of Medicine, Sapporo, Japan
}

\begin{abstract}
Summary
Mobilities of cord blood granulocytes were studied using the agarose plate method and Boyden's chamber method. In the agarose plate, granulocytes of cord blood were shown to have moderately decreased responses in chemotaxis and chemokinesis induced by Escherichia coli-derived chemotactic factor and/or zymosan-activated serum, whereas they were shown to have a normal capacity of random mobility. Although their distance and index of chemotaxts or chemokinesis in the agarose plate were significantly less than those of adult granulocytes, response rate in both types of mobility were evidently higher compared with those in patients with chemotactic defect. Furthermore, there is a difference between chemotactic responses of cord blood granulocytes to $\mathbf{E}$. coli-derived chemotactic factor and to zymosan-activated serum in the agarose plate method. Using the latter, a more distinguishable difference between chemotactic responses of cord blood granulocytes and adult granulocytes was shown.

The Boydem's chamber method tended to show a more signiffcant difference between chemotactic responses of granulocytes of cord blood and adults than in the agarose plate method.

\section{Speculation}

The impaired chemotactic function of the cord blood granulocyte may be due to developmental immaturity in chemokinetic and/or chemotactic response, and the degree of impairment may be moderate.
\end{abstract}

Numerous studies regarding the functions of neonatal leukocytes are available $(3,5,7-9,12)$. This is because various bacterial infections are apt to occur in the neonatal periods. In general, some functions of neonatal leukocytes are considered to be involved in developmental immaturity.

There are two methods, namely, Boyden's chamber method and agarose plate method, available clinically for the evaluation of chemotaxis of human leukocytes. The Boyden's chamber method is well known $(1,8,10,12-14)$. The agarose plate method that was introduced by Nelson et al. recently (11), is simpler and has a higher reproducibility compared with the Boyden's chamber method, although it remains uncertain whether the same phenomenon can be observed in these two assay systems.

Recently, a report has become available regarding the chemotactic activity of neonatal leukocytes in the agarose plate method as reported by Klein et al. (7). They reconfirmed in their study that a decreased chemotactic response in the newborn was present as shown by Miller ( 8 ) previously, who used the Boyden's chamber method, in which the capacity of random mobility and chemotactic response which means cell response when it comes in contact with the chemotactic factor cannot be analyzed separately.

Thus, we studied the chemotactic and chemokinetic responses of cord blood granulocytes separately from their capacity of random mobility in the agarose plate method, and the results were compared with those obtained by Boyden's chamber method.

\section{MATERIALS AND METHODS}

\section{LEUKOCYTES PREPARATION}

Heparinized cord blood was mixed with one-tenth volume $2 \%$ methyl cellulose solution (Nakarai Chemicals, Japan) and was allowed to settle at room temperature for $30 \mathrm{~min}$. The leukocytes in the supernatant were sedimented by centrifugation at $250 \times \mathrm{g}$ for $10 \mathrm{~min}$ at $4^{\circ}$, and the cells were washed in ice-cold Hanks' solution. Then mononuclear cells were separated by a modification of the method of Böyum (2).

Leukocyte preparations in Hanks' solution were layered on top of Ficoll (Pharmacia)-Hypaque (Winthrop) solution (24 parts $9 \%$ Ficoll +10 parts $33.9 \%$ Hypaque) and centrifuged at $250 \times \mathrm{g}$ for $45 \mathrm{~min}$ at $4^{\circ}$. The mononuclear cell layer from the top of the gradient and Ficoll-Hypaque solution were gently aspirated and discarded, and the cell button was resuspended in $0.2 \mathrm{ml}$ phosphate-buffered saline which did not contain $\mathrm{Ca}^{2+}$ and $\mathrm{Mg}^{2+}$. Then the contaminating erythrocytes were disrupted by the hypotonic shock method. After washing two times with phosphate-buffered saline not containing $\mathrm{Ca}^{2+}$ and $\mathrm{Mg}^{2+}$, the cells were resuspended in the phosphate-buffered saline at a cell concentration of $1 \times$ $10^{8} / \mathrm{ml}$. Cell aggregation was completely prevented by the elimination of $\mathrm{Ca}^{2+}$ and $\mathrm{Mg}^{2+}$ from the medium where cells were suspended. Although these purified granulocytes were used in the agarose plate method, leukocyte preparations before the step of separation of mononuclear cells were used in the Boyden's chamber method.

\section{CHEMOTACTIC FACTOR PREPARATION}

In the present experiments, two kinds of chemotactic factors were used. A bacterial chemotactic factor was produced by overnight growth of $E$. coli grown on heart infusion broth at $37^{\circ}$. Then the culture broth was passed through a $0.22 \mu \mathrm{m}$ filter. Activated serum was obtained by incubation of fresh human $A B$-type serum with zymosan (final concentration $50 \mathrm{mg} / \mathrm{ml}$ serum) at $37^{\circ}$ for 30 min. After centrifugation $(1085 \times g)$ the supernatant was sterilized by filtration. Then it was inactivated at $56^{\circ}$ for $30 \mathrm{~min}$. These factors containers were stored at $-70^{\circ}$ until use.

\section{ASSAY OF LEUKOCYTE MOBILITY AND CHEMOTAXIS}

Agarose plate method (Fig. I). This was performed by a minor modification of the method of Nelson et al. (I1). The agarose plate was prepared by placing $3 \mathrm{ml} 1 \%$ agarose (Behringwerke) solution in Medium 199 containing $10 \%$ heat-inactivated fetal calf serum into $35-x \quad 35-\mathrm{mm}$ Falcon plastic dishes. When chemokinesis, namely, the enhancement of random mobility by the chemotactic factor, was assayed, the chemotactic factor was added to the agarose plate at a final concentration of $10 \%$. After the agarose gelled, 3- $\times 3-\mathrm{mm}$ wells were made by a stainless steel punch in the agarose plate, and $10 \mu \mathrm{l}$ cell suspensions and chemotactic factor were placed into it as shown in Figure 1 .

After $3 \mathrm{hr}$ of incubation in a $5 \% \mathrm{CO}_{2}$ incubator at $37^{\circ}$, the three 


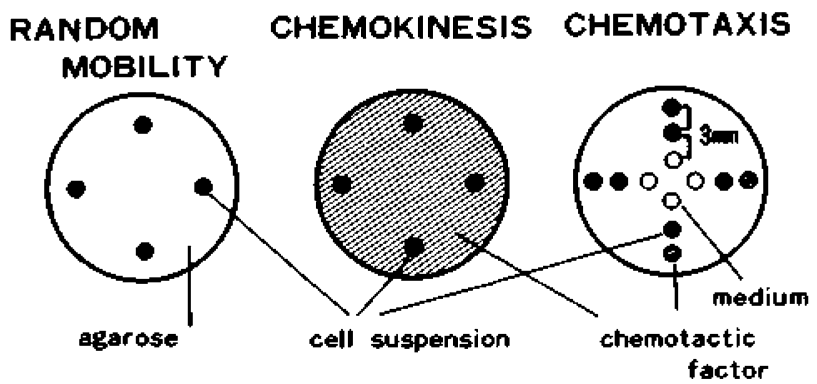

Fig. 1. Agarose plate method employed in the experiments. Three types of granulocyte mobility were measured in this method. The oblique lines mean the presence of chemotactic factor.

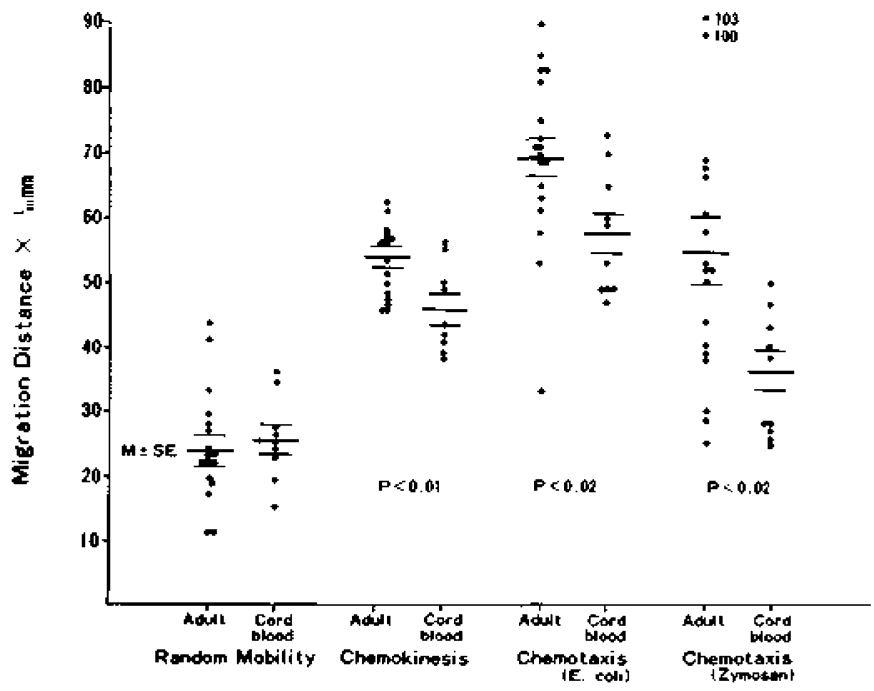

Fig. 2. Distances of random mobility, chemokinesis, and chemotaxis of granulocytes of the cord blood or adult. Chemokinesis was induced by $E$. coli-derived chemotactic factor, and chemotaxis was induced by $E$. coliderived chemotactic factor or zymosan-activated serum.

types of granulocyte mobility were measured as follows: Random mobility = linear distance moved from the margin of the well toward the outside under no factor; chemokinesis = linear distance moved toward the outside under uniform chemotactic factor; chemotaxis = linear distance moved toward chemotactic factor (under a chemotactic gradient); chemotactic index = linear distance moved from the margin of the well toward chemotactic factor/linear distance moved from the margin of the well toward the control mediun; chemokinetic index = linear distance moved toward the outside in the agarose-containing chemotactic factor/ linear distance moved toward the outside in the agarose not containing chemotactic factor. Distance was measured by inverted microscope with an ocular grid. In the case of random mobility and chemokinesis, four directional movements were measured and the mean distance was used in the calculation.

Chamber Method. This was performed by a modified Boyden microchemotaxis chamber (1) using a Millipore filter with a $3 \mu \mathrm{m}$ mean pore diameter and thickness of $140 \mu \mathrm{m}$ (slight modification of Corney's method (4)). The lower compartment was filled with $E$. coli bacterial factor as a chemotactant and $0.5 \mathrm{ml}$ of leukocyte suspensions $\left(2.0 \times 10^{6}\right.$ polymorphonuclear leukocytes $\left./ \mathrm{ml}\right)$ was placed in the upper portion of the chamber.

After incubation at $37^{\circ}$ for $3 \mathrm{hr}$, the filter was moved and stained with hematoxylin. Leukocytes were counted both in the upper side and lowermost layer of the filter in 10 high-power fields and expressed as percentage of cells migrating (13).

All of these experiments were carried out in duplicate or triplicate.

\section{RESULTS}

\section{RANDOM MOBILITY OF CORD BLOOD GRANULOCYTES (FIG. 2)}

This was compared with that of adult granulocytes. There was no significant difference in distance of random mobility between the two types of granulocyte.

\section{CHEMOKINESIS OF CORD BLOOD GRANULOCYTES INDUCED BY $E$. COLI-DERIVED CHEMOTACTIC FACTOR (FIGS. 2 AND 3)}

Cord blood granulocytes stimulated by $E$. coli-derived chemotactic factor showed enhanced random mobility sufficiently, namely, chemokinesis. There was a significant difference in distance of chemokinesis between granulocytes of cord blood and adults $(P<0.01)$, and the former showed a decreased index, but was not significant $(P<0.1)$.

\section{CHEMOTAXIS OF CORD BLOOD GRANULOCYTES INDUCED BY E COLI-DERIVED CHEMOTACTIC FACTOR OR ZYMOSAN- ACTIVATED SERUM (FIGS. 2 AND 3)}

Chemotaxis was assessed in cord blood granulocytes obtained from 10 term newborns. Mean cord blood granulocyte chemotaxis induced by $E$. coli-derived chemotactic factor was $57.3 \pm 9.5$ (SD), which was significantly less than the granulocyte chemotaxis of adults (mean, 69.4 \pm 13.4). There was a significant difference also in chemotactic index. Using zymosan-activated serum, mean cord blood granulocyte chemotaxis was $35.2 \pm 9.5$ (SD), significantly less than that of adults (mean, 54.3 \pm 21.7 ). Moreover in the chemotactic index, a highly significant difference was detected between them.

\section{CHEMOTAXIS OF CORD BLOOD LEUKOCYTES IN BOYDEN'S CHAMBER METHOD (FIG. 4)}

Cord blood leukocytes showed a consistent and marked deficiency in response to $E$. coli-derived chemotactic factor. There was a highly significant difference between the two types of leukocytes.

COMPARISON OF CHEMOTACTIC RESPONSE BETWEEN GRANULOCYTES OF CORD BLOOD AND THE PATIENTS WHOSE GRANULOCYTES SHOWED CHEMOTACTIC DEFECT (TABLE I)

In the above experiments, we confirmed that the chemotactic response of cord blood granulocytes was less than that of adult

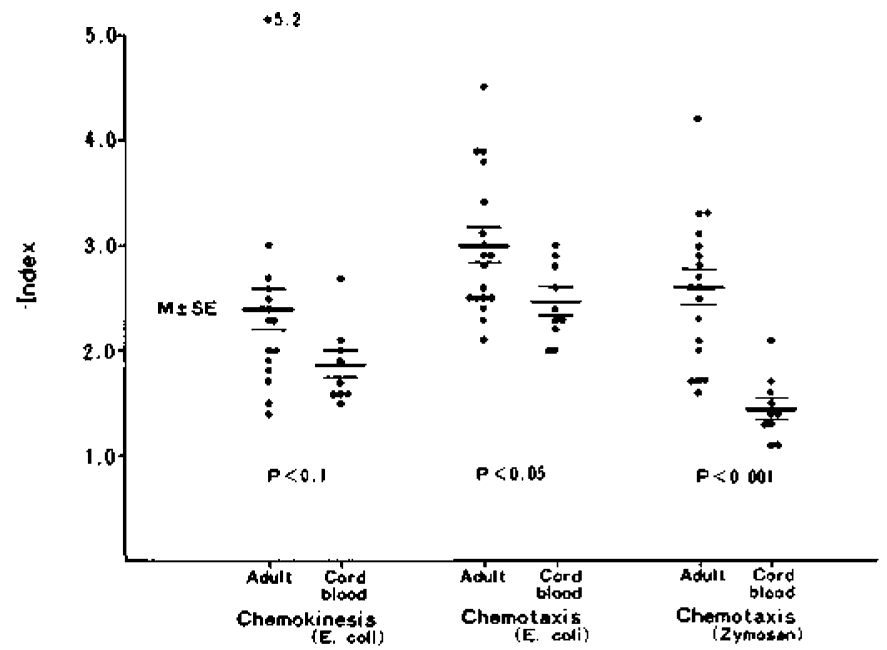

Fig. 3. Indices of chemokinesis induced by $E$. coll-derived chemotactic factor and chemotaxis induced by two kinds of chemotactic factor. Index was calculated as follows: chemokinetic index $=$ linear distance moved toward outside in the agarose-containing chemotactic factor/linear distance moved toward outside in the agarose-containing no factor; chemotactic index = linear distance moved toward chemotactic factor/linear distance moved toward control medium. 